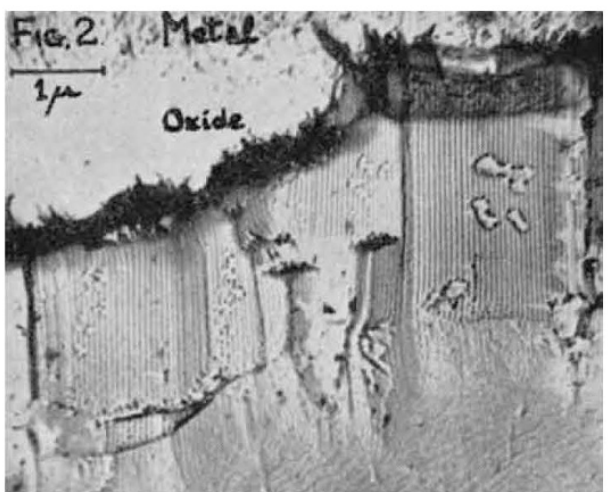

it appears that the pore structure is only revealed in this way at places where minute fragments have been chipped out of the oxide layer during the preparation of the specimen surface.

This investigation is being continued and forms part of a research programme of the Food Investigation Organization of the Department of Scientific and Industrial Research on the development of the Torry capacity-resistanco hygrometer. The work is being carried out to ensure that an instrument of standard characteristios, free from hysteresis and stable over $a_{b}$ wide range of operating conditions, will bo produced. It is hoped to publish a fuller account of the work elsewhere.

Department of Chomistry,

C. J. L. Booker

J. L. WooD

Sir John Cass College, London, E.C.3.

\section{A. WALSH}

Department of Applied Physics,

Northampton Polytechnic Institute, London, E.C.l. March 22.

${ }^{1}$ Fischer, H., and Kurz, F., Korrosion und Metallschutz, 18, 42 (1942). Edwards, J. D., and Keller, F., Trans. A mer. Inst. Min. Met. Eng, 156, 288 (1944). Huber, K., J. Colloid Sci., 3, 197 (1948). Soc., 1.00, 411 (1953)

${ }^{2}$ Bradley, D. E., J. Inst. Metals, 83, 35 (1954).

\section{Reactivity of Freshly Formed Steel Surfaces}

Ir is now an established fact that freshly formed metal surfaces have an inherently high reactivity. A probable confirmation of this fact was noticed recently when specimens of mild steel were broken by impact at sub-zoro temperatures. Fracture was predominantly of the clcavage type at the tomperatures concerned, and the work undertaken necessitated an examination of the fracture surface. It was noticed that this surface corroded far more rapidly than would normally be expected in the laboratory atmosphere. Ten minutes after fracture, definite corrosion films could be detected and the well-known rust-coloured deposit appeared shortly afterwards.

Undoubtedly the fracture surface would be covered by a film of adsorbed moisture and, in viow of the recent work on the production of hydrogen peroxide on freshly formed metal surfaces ${ }^{1}$, it is likely that the oxidation mechanism was associated with hydrogen peroxide formation as suggested by Haber and Woiss :

$$
\begin{aligned}
& \mathrm{H}_{2} \mathrm{O}_{2}+\mathrm{Fe}^{++} \rightarrow \mathrm{Fe}^{+++}+\mathrm{OH}^{-}+\mathrm{OH} \\
& \mathrm{OH}+\mathrm{Fe}^{++} \rightarrow \mathrm{Fe}^{+++}+\mathrm{OH}^{-} \\
& \mathrm{Fe}^{+++}+3 \mathrm{OH}^{-} \rightarrow \mathrm{Fe}(\mathrm{OH})_{3}
\end{aligned}
$$

Whatever the corrosion mechanism, the fact remains that freshly cleaved steel surfaces are extremely reactive. The method of cleaving specimens at an appropriate temperature would probably be useful in the investigation of the reactivity of metal surfaces.

\section{A. Prince}

Engineering Laboratory, University, Southampton. March 22.

${ }^{1}$ Grunberg, L., Proc. Phys. Soc., B, 66, 153 (1953).

\section{A Method of locating Interfaces in Oil Pipelines}

I $\mathrm{T}$ is often desirable to locate or follow the interface between two oils or fuels during transmission along a pipeline. Present methods include those based upon sampling techniques or radioactive labelling of the interface. The first of these is tedious and slow, and the second method involves the injection of a radioactive marker substance at the interface, with the attendant difficulties of handling radioactive material in the product itself.

An alternative method utilizes the variation of hydrogen content of the two liquids. Hydrogen contents of bulk liquids may be easily compared by the use of a neutron-backscatter or transmission technique. A portable source of fast neutrons can be placed outside the pipe. The neutrons entering tho liquid are moderated by scattering from the hydrogen atoms, and the concentration of slow neutrons which emerge from the pipe (either in a forward or backward direction) will be dependent on the bydrogen content of the liquid in the pipe. These can be measured with the use of standard equipment incorporating a boron trifluoride counter.

Preliminary laboratory tests indicate that the measurement of either scattered or absorbed neutrons can differentiate between premium and commercial grade fuels by a 5 per cent change in reading. A further change of 10 per cent occurs between commercial fuel and paraffin.

In the event of the two liquids having the same hydrogen content, if the interface could be labelled with minute quantitios of a salt of boron, gadolinium or other suitable material, then it could be located. very easily, since these additives absorb the slow neutrons very strongly.

Theso methods have the great advantage over standard radioactive methods that they do not involve the inconvenience of handling radioactive material in solution, or the necessity of obtaining a regular supply of radioactive isotopes.

The preliminary work carried out on neutronscattering methods indicates their considerable potentialities, and techniquos will be further investigated.

$$
\begin{aligned}
& \text { D. B. SMith } \\
& \text { G. R. CHuROH }
\end{aligned}
$$

Atomic Energy Research Establishment, Harwell, Nr. Didcot, Berkshire.

May 31. 